\title{
From Forever Foreigners to Model Minority: Asian American Men in Sports
}

Authors' contribution:

A) conception and design

of the study

B) acquisition of data

C) analysis and interpretation

of data

D) manuscript preparation

E) obtaining funding

\section{Yomee Lee}

State University of New York, USA

\section{ABSTRACT}

Despite their long history in the United States, relatively little scholarly attention has been paid to Asian Americans and their lived experience in sports. The purpose of this study was to give voices to Asian American men by focusing on their experiences in sports. In particular, this study examined the experiences of East Asian and Southeast Asian American male college students who were often perceived as "foreign" and "pejoratively feminine" racialized minority yet participated in sports that were associated with dominant masculinity in the U.S. The setting of the study was as a predominately White institution located in Upstate New York where Asian Americans make up about one percent of the total student population. Qualitative research method was employed for the study. Six Asian American male students were recruited through snowball and purposeful sampling methods. In-depth interviews were conducted to reveal the rich stories of these Asian American men. The research showed that the stories of Asian American male college students were much nuanced and complicated. Specifically, this study revealed that Asian American men were constantly otherized as "forever foreigners" who did not have a legitimate citizenship in the United States. Also, Asian Americans faced unique ideas about their manhood that either highlighted emasculated and feminized masculinity or hyper-masculinity. In dealing with these situations, Asian American men employed unique cultural strategies to challenge and resist racial stereotypes through sports.

KEYWORDS Asian American men, race, masculinity, intersectionality, sports

\section{Introduction}

Despite the fact that Asian Americans are the fastest growing minority in the U.S. (U.S. census bureau, 2012) and that they have been part of this country as early as the 1700s (Takaki, 1998), they continue to remain invisible and silent. Except for limited fields of science, medicine and technology, many Asian Americans are not recognized and continue to be marginazlied, particularly in the "testosterone areas of sports, politics and big businesses" (Tizon, 2014).

Given the role of athletics and sports as a primary cultural site to reproduce, reinforce and reaffirm dominant ideals of masculinity (Anderson, 2005; Coakley, 2015; Kimmel, 2011; Messner, 1992), the underrepresentation of Asian Americans in sports further reinforces the notion of Asian American men as weak, asexual and effeminate individuals who lack strong masculine characteristics. Such marginalized masculinity perceived in Asian American men is positioned in polar opposite to the idealized masculinity of their White counterparts (Hirose, \& Pih, 2010). Asian Americans have long suffered from ideological assaults that are based on gender and sexuality constructed as a process of racial domination in the U.S. (Espiritu, 
2008). Perhaps the irreconcilable and conflicting images of "pejoratively feminine" Asian American men (Cheng, 1996) participating in forms of sports that emphasize hegemonic gender ideologies provide at least partial explanation for the lack of attention on the studies of Asian Americans in sports. According to one study, even Asian Americans themselves viewed sports as a highly racialized arena, reserved primarily for the dominant White Americans; Asian Americans and sports as a research topic did not make much sense (Lee, 2015).

It is only in recent years that research examining the sporting experiences of Asian Americans has begun to develop (King, 2015; Thangaraj, 2012, 2015; Thangaraj, Arnaldo, \& Chin, 2016). Similarly, this study focuses on the lived experiences of Asian American men in sports, specifically the sporting experiences of East Asian and Southeast Asian American male college students. In discussing the shifting boundaries of the identity of Asian Americans, Lowe highlighted "heterogeneity, hybridity and multiplicity" in the characterization of Asian American culture (Lowe, 2000). Studying the experiences of Asian American men includes a unique challenge as Asian American culture is fragmented and diverse. This research is limited to only a fraction of the broader group of Asian Americans as it explores Americans of East Asian and Southeast Asian origins. The purpose of this study was to privilege the marginalized voices of those whose experiences were uniquely shaped by the interplay of racial and gender dynamics that produced different stories. Examining Asian American men in sports is a fitting object of inquiry because of the two contrasting ideas: hegemonic masculinity of dominant forms of sports and subordinate masculinity of Asian American men (Connell, 2005). Inevitably, cultural negotiations and compromise, power struggles and "hegemonic bargaining" are bound to happen as Asian American men participate in sports (Chen, 1999). The following section explores the specific ways through which Asian Americans are marginalized and otherized by racialization in the United States.

\section{Discrimination, stereotypes and otherization of Asian Americans}

Asian Americans' marginalized status as "racialized ethnic minorities" are reinforced and reaffirmed by ongoing misconceptions and misrepresentations surrounding them (Kibria, 2002). Some of the most commonly affixed stereotypes about Asian Americans include the notion that they are perpetual aliens, forever foreigners whose loyalty to the U.S. is constantly at question. Many Asian Americans state that they often encounter the question, "Where are you from?" regardless of the length of their stay in the United States (Chou, \& Feagin, 2015; Wu, 2002). The question stems from the perception that Asian Americans are not a legitimate part of the country; they are seen as strangers and outsiders that are incapable of assimilating into the U.S. Asian Americans are positioned in an intersectional status by both race and foreignness ( $\mathrm{Lu}, \&$ Wong, 2013).

Another stereotype associated with Asian Americans is that they are a model minority. The model minority myth reinforces the idea that Asian Americans are highly intelligent, hard working, diligent, and gifted in math and science. In short, they are seen as the "living proof of power of the free market and the absence of racism" in this country, the minority that realizes the American dream of "you can be who you want to be". (Wu 2002, p. 44). Seemingly a compliment, the model minority myth is problematic and controversial. This model minority idea vastly generalizes Asian Americans, ignoring the diversity and multiplicity that exists within the group. There are more than 30 ethnic groups under the umbrella of Asian Americans, however they are lumped into a monolithic Asian identity (i.e., the notion that all Asians are Chinese) through the notion of model minority.

While the model minority myth impacts both Asian American men and women, this stereotype has specific implications to Asian American men as it relates directly to Asian American masculinity. Since "smart" is negatively associated with pejorative terms like nerd, geek, bookworm, etc. the stereotypical association of Asian American men with high intelligence works against them. The model minority stereotype of "nerdy and geeky" Asian American men strips them of strong and powerful masculinity as "nerd" perpetuates frail, soft and pejoratively feminine characteristics, contrasted to strong and rough masculine characteristics (Cheng, 1996, Lu and Wong 2013). The ideological assaults on Asian American men as effeminate, emasculated, and androgynous de-sexualized uni-dimensional caricatures have been an ongoing 
part of popular media and literature in the U.S. history (Eng, 2001, Espiritu, 2008). The "symbolic castration" of Asian American men continues to devoid them of any sense of strong manhood and manliness. In essence, the powerful cultural message conveyed is: if hegemonic masculinity is the most honored and privileged way of being men in the United States, Asian and Asian American masculinity is the one of the least desirable ways of being men.

Then, when Asian American men participate in athletics and sports, specifically forms of sports that highlight the dominant notions of masculinity, they are faced with contrasting and conflicting identities that further complicate their lives. What is it like to be situated in this position and participate in sports as Asian American men? This study attempts to provide some insight into understanding their experiences.

\section{Critical Race Theory and intersectionality}

This research is informed and inspired by Critical Race Theory (CRT), which offers several important organizing principles. According to Soloranzo and Yozzo (2002), one of the key elements of CRT is the notion that race and racism intersect with other forms of oppression and discrimination such as gender and class relations (Hylton, 2005, 2010; Soloranzo, \& Yozzo, 2002). The notion of intersectionality is a central part of critical race analysis because focusing on race alone does not account for the richly textured experiences of Asian American men whose lives are profoundly influenced by a specific set of ideas about Asian American manhood.

Intersectionality emphasizes that there are multiple forms of systems of oppression such as gender, race, sexuality, and class and that these systems mutually construct, reinforce and articulate with one another rather than operating separately (Anderson, \& McCormack, 2010; Collins, 2000). Although the concept of intersectionality was developed by Black feminists, the same idea can be extended to other groups of people who experience marginalization through multiple forms of oppressions including Asian American men (Crenshaw, 1989; Harris, 1990). Through the concept of intersectionality, one can see how these systemic prejudices produce and reinforce the idea of Asian American men not simply as "men of Asian-descent" but "men of Asian-descent that are inferior, incomplete and unwanted". As Espiritu insightfully argues that the racialization of Asian American manhood highlights the interconnections of race, gender, and class and that the ideological representation of Asian American men is key to justifying and maintaining white male supremacy (2008, p 121).

The concept of intersectionality and its related ideas allows us to examine the lived experiences of those who are placed in the social periphery in a much more nuanced and detailed manner. CRT and intersectionality are both grounded in the lived experiences of people who are marginalized and have been utilized in this research (Anderson, \& McCormick, 2010).

\section{Research methods}

The setting of the study was at predominately White institution in Upstate New York where Asian Americans make up about one percent of the total college student population. There are approximately 7000 students enrolled in the university, of which about 70 are Asian Americans. Once the study was approved by the institutional review board of the university, participants were contacted for in-depth interviews. Two recruitment methods were employed to recruit the interviewees: purposeful sampling method and snowball sampling method. Six Asian American male college students were recruited from diverse ethnic backgrounds, including Chinese, Korean, Vietnamese and Filipino Americans. Table I provides a summary list and the description of the interviewees that include their names (pseudonym), age, ethnicity, major, and immigrant generational background.

Before the interview began, all six participants signed the informed consent form that was approved by the institutional review board of the university. The length of each interview ranged from 45 minutes to 2 
hours and 15 minutes. All the interviews were recorded and the contents were fully transcribed. After the transcripts were read multiple times, major themes were identified through content analysis and coding.

According to Patton (1990), multiple types of triangulation strategies can be used for increased credibility and accuracy of qualitative research. In this study, analysts triangulation method was employed to reduce a potential bias of a single researcher. This particular strategy involves "having two or more persons independently analyze the same qualitative data set and then compare their findings" (Patton, 1990, p. 468). An expert in qualitative research reviewed the transcribed interview data and identified a number of emergent themes of the research. After exchanging perspectives and thoughts on the data analysis, final themes were identified and chosen. In addition to triangulations, reflexivity was employed to increase the credibility, trustworthiness and rigor of the study (Gringeti et al., 2013).

Table 1. Summary list and description of interviewees

\begin{tabular}{lcccc}
\hline Name & Age & Ethnicity & Major & Generation $^{\mathbf{1}}$ \\
\hline Dave & 20 & $\begin{array}{c}\text { Chinese and } \\
\text { Vietnamese }\end{array}$ & Phys. Ed. & Second \\
Steve & 23 & Korean & Education & Second \\
Ji Hoon & 20 & Korean & Business & One point five \\
Huang Fu & 19 & Chinese & Biology & One point five \\
James & 20 & Filipino & Art & Second \\
Ed & 22 & Vietnamese & Phys. Ed. & Second \\
\hline
\end{tabular}

Source: own study.

In terms of the author's positionality, the researcher herself is Asian American who spent a significant about of time in both the U.S. and Asia (Korea). After being born in the U.S., the researcher moved to Korea when she was five years old. The researcher received most of her formal education in Korea and moved back to the U.S. after graduating from college for her graduate degree. Since earning her degree, the researcher has been working as a professor in a predominantly white university for a number of years. The researcher's background as an Asian American woman who experienced being raced and racialized in various cultural contexts has been helpful in connecting and building rapport with the interviewees. The researcher's position and the background were critical in capturing the nuances and complexities for the data analysis section, given the weight of race relations and racial identity of this research. As scholars argue, when researchers share the same cultural characteristics with the participants, they are in an excellent position to unveil ideas and perceptions related to the research (Fletcher, 2014).

\section{Data presentation}

\section{1. "Are you Chinese? Lalalalala." - Forever foreigners}

The narratives of Asian American men revealed that they were constantly being otherized through various processes. One includes their experiences of begin categorized as "forever foreigners". The intensity of the notion of "forever foreigners" ranged from "Where are you from?" or "Wow, you speak great English" to the more ominous "Go back to your own country". Steve shared his story of playing varsity soccer:

From the crowd, I hear [racial slurs] and stuff like that when I'm playing or like when the ball's out of bounds and I pick up a ball near the sideline and I hear something like "Oh, go back to your country!" or "Are you Chinese, lalalalala." or some jokes about Chinese food and stuff like that. I just laugh it off. Cause I know I can shut 'em down when I'm on the field.

QUESTION: What do you mean "shut 'em down"?

\footnotetext{
1 There is not a universal way of defining generational differences. In this article, one point five generation Asian Americans refer to those who were born outside of the U.S. and came to the U.S. when they were young and second generation Asian Americans are those who were born in the U.S. See Kibria (2002).
} 
I don't hear anything. I can show it on the field that I am so much better than your team. Like I can shut you down from talking like that. Stuff like that it's really funny (said in a serious tone of voice).

An almost identical story was shared by Ji Hoon. He played a variety of sports including swimming, soccer and lacrosse. He was often called "slinky eyes, chink, or go back to Korea or whatever you are". When he was asked how he responded to the racial slurs, he explain as follows:

I couldn't DO anything about it (He placed his hands down in a frustrated motion.). [...] I guess I kind of talked back a little but I couldn't punish the kid. I guess I was more aggressive [and] after that, kind of let it go. [...] Yeah, 'cause there's an audience watching and it was just high school sports, too. I would have gotten into trouble. [W]hen high school sports [...] got competitive, that's when they did it. By that time, I'd already gotten suspended. Maybe if it was the first time, maybe I might have punished the kid. But I already got suspended twice before that.

A number of interviewees shared a similar experience when they participated in sports. When the interviewees encountered racist remarks and slurs, most of them handled them in a seemingly passive way; by choosing to "ignore", "tune out" "just focus on the game" or "laugh off" because they knew they would be scrutinized closely and also be highly visible as racial minorities during competitions. However, occasionally they reacted to racial slurs with the use of physical force or violence. Dave who played soccer, basketball and Lacrosse reported an incident when he was playing soccer in high school.

[Actually] [O]ne time I got into a fight in the middle of the game. Well, we were playing soccer at that time, and I pushed him [an opponent] really hard and he fell and he got really mad. And he was a black kid and he was calling me "Gook" the whole game. He got non-stop in my ear the whole game, toward the end of the game, the ball was on the other side of the field and no one was watching. He came and head-butt me a little bit, so I just turned and swung at him cause I was done with it. I just swung at him and he just fell to the floor and I walked off the field.

In dealing with racial situations and discrimination, many of the interviewees said that they either "tuned [racial slurs] out", especially in the settings of sports, or made light of the situations by considering them as a mere joke. Although they said that they were "tuning out" or "shutting them down" and "don't hear anything", the lingering impact of such racial slurs and assaults by those who are experiencing them were not diminished or insignificant. If these Asian American men were truly able to ignore or tune out those situations, they would not have been able to recite and explain the incidents in such a detailed manner even when some of these incidents happened years before. The intensity and powerfulness of the stories shared by these interviewees suggest that they are victims of complex forms of everyday racisms that become cumulative and compounded over time. Hylton (2010) poignantly addresses the profound impact of experiencing racisms and racial discriminations as follows:

"The accumulated emotional costs of small acts can be easily misunderstood, ignored or discounted, but not for those who have experience of these everyday. Those who have been humiliated by a joke, an off-hand comment, or some other action that could be construed as 'low impact', 'ambiguous' or 'ethnically excusable', would understand that the totality of these experiences could make the last 'trivial' racist act the emotional tipping point" (Hylton, 2010, pp. 348-49).

Hylton's argument is echoed in the stories of Dave and Huang Fu that involved violence as a reaction to coping with racist acts and comments. The incidents involving violence suggest that being a part of the racialized process that continuously marginalizes them as minorities accumulated to the point where these men just "could not take it any more" or "had gotten more aggressive" over time.

2. Model Minority and the feminized image of Asian American men

Another important layer of my research explores narratives about Asian American manhood that are 
perpetuated by the dominant U.S. culture. Assumptions about Asian American men range from hypermasculinization to demasculinization. The findings of this study were consistent with current literature on Asian American manhood, which discusses both the aggressive and threatening ideas of Asian American men (manifested in the Yellow Peril and Kung Fu mater) and the effeminate and emasculate stereotypes (for example, socially awkward and nerdy Long Duk Dong in the movie Sixteen candles and a flamboyant drug lord Leslie Chow in the movie The Hangover) (Espiritu, 2008; Lu, \& Wong, 2013; Shek, 2006). Ed shared that people often made assumptions that he was a martial artist:

Although I never heard the word 'Chink' in high school, but some people that I wasn't really friends with, if we would get into an argument or something like that, they'd be like 'Oh, I don't want to fight him. He's Asian, he must be good at Karate or he must know something like that.' That guy, I've known him but he was not really a friend, he's one of those act like a tough guy kinda thing, cocky kind of person. You run into people like that all the time in life. He was one of those guys, immature teenagers around that time. It was like 'who's more macho?' Stuff like that.

Among the interviewees, Ed was the only person who explicitly talked about the assumption of hypermasculinity for Asian American males. Not surprisingly, all the interviewees (including Ed) encountered stereotypes of Asian American men related to the other extreme: the desexualized, effeminate and weak images of Asian American manhood. For example, all the interviewees shared how people constantly assumed that these men were highly intelligent people who were especially good in math and science. Although all the interviews experienced stereotypical racial assumptions about their manhood, some did not see themselves as a direct target of the racial discourse as they viewed themselves as "not the typical Asian American men". Rather, they were academically underachieving jocks who loved playing sports like their White counterparts, therefore, they had no understanding of what it was like to be emasculated Asian American men.

While some racial experiences were subtle and indirect, some were quite blatant and overtly racist. James talked about how non-Asian Americans (mainly White Americans) specifically asked him questions about emasculated images of Asian American men. He elaborated as follows:

They'll ask "Oh, so do Asians really have tiny dicks?" or whatever, I would be like "Hmmmm... Do you want to find out?". Or if it's a girl, I'd be like, "Why would you want to know? Are you interested [in me]?". Girls will ask me that all the time. But I'd figure if a girl's asking me, specifically like, "Oh, is your dick small?" if you're asking me about it, there must be some interest there, so I'd be like I'll ignore the question or just flip it.

He later stated that question was often asked mockingly or jeeringly, as if those who were asking such questions were solely interested in seeing James' reaction, rather than the actual answer to gave. James, as well as other subjects, talked about encountering racial jokes numerous times throughout the interviews. These college age men, who were the target of these ethnic jokes, did not see the ridicule as humorous or funny. Rather, they experienced ethnic jokes as dehumanizing and humiliating, and were uncomfortable with the mocking of broader stereotypes aimed at Asian American men (King, 2006).

\section{Dealing with racism - Cultural strategies employed by Asian American men}

While the backgrounds of the Asian American men were diverse, they all shared powerful stories highlighting how the racialization of Asian American manhood relegated them into an inferior position in the racial hierarchy in the U.S. As the interviewees stated, the racial assumptions and attitudes they encountered were a regular part of their everyday lives. Then, how did these Asian American men cope with this debilitating atmosphere and oppressive comments and reactions that were a steady occurrence in daily life?

There were some interesting strategies which these Asian American men employed as they dealt with their space in the racial hierarchy in the U.S. One way to resist the negative perceptions of Asian American men was to embrace athleticism and sports (Kimmel, 2011; Thangaraj, 2015). Most interviewees were quick to admit that they were not the "typical Asian guy" and claimed what had separated them from other Asian 
Americans from school was their identity as "jocks". The following section explores Asian American men and their relationships with sports, race and masculinity.

\title{
Resisting marginalization through sports
}

According to the narratives of the interviewees, it was evident that race served as a primary form of their identity inside and outside of sports. In other words, they stood out as a person of Asian background, particularly in an educational setting with little racial ethnic diversity. Ironically, sports provided these Asian Americans a means to "de-Asianize" themselves, mainly due to the contrasting ideas between dominant forms of sports and the popular notions of Asian manhood.

The participants of the study explicitly rejected the idea of a typical Asian guy as portrayed in the model minority myth. They also happened to play a wide variety of sports. By participating in sports, these Asian American men rejected and resisted stereotypes of Asian American manhood and established a different masculine identity by conforming to the idealized dominant White manhood through physical prowess. Steve stated that he was known as "Steve, the soccer player" and agreed that his image as an athlete separated him from the rest of the Asians at school. Similarly, Ji Hoon talked about weightlifting, which provided him with a means to break away from the stereotyped Asian American manhood. He explained:

\begin{abstract}
[W] hen I wanted to get bigger, I would lift for two hours but I used to weigh like 140 pounds in junior, senior years. I am 5-8 and 165 pounds, but I just remember how small I was in high school and I started lifting $a$ lot and lot and lot and then I am not huge, but I'm bigger than most Americans and some white Americans here or African Americans and that gives me a little satisfaction. 'Cause mostly Asians are really, really scrawny and skinny.
\end{abstract}

Both Steve and Ji Hoon's stories suggest that their experience in sports included the process of resisting the notion of typical Asian men with their purported small size and weakness. Involvement in sports provided a process for "de-racing" or "de-Asianizing" themselves. Most interviewees embraced statements such as "You are not like any Asians that I know". or "You're the coolest Asian guy I've ever known". made by their White friends. Conforming to ideals of hegemonic masculinity through sports became one of the strategies to cope with ideas about the racialized manhood of Asian Americans.

While sharing his story in sports, James drew an interesting parallel between his language ability (English) and athletic skills (swimming). During the interview, James emphasized the importance of being able to speak standard American English so that he could be more accepted by Americans. He did not want to develop any regional dialect within America so he made a concerted effort not to develop a typical Brooklyn accent when he was living in New York. James elaborated on how language as well as sports became an important means for him to be more accepted by the dominant American society. He explained:

I treated [swimming] as if I was, like, learning English well. In like, I'm really good at this so people will accept me now, a little bit more. So I focused hard on it so people would be like "Oh wow, what do you do? Do you play sports?", "Yeah, I swim". "Wow, we don't hear that [Asian men swimming] a lot, that's cool!"

James is currently enrolled in a college swimming club that includes over 30 athletes. Being the only Asian athlete on the team, he had some his unique experience in sports:

It's funny 'cause when I was at Binghamton, I noticed there was only me, the only Asian on my team and one other Asian on the other team. There were a lot of white faces so alright, I made a show, stretching, tried to really push myself.

QUESTION: Why do you think you were pushing yourself?

Okay, there was one event, the 500, 20 laps, that no one signed up for. They just chose to skip it, so I was like, I've swam way more than the 20 in practice just by myself, so I was like "let me do this". And I was the only one in the pool and I was like "Okay, let me just show these people that 
this little Asian kid can really do this". Probably not my best moment, I was very vain, very selfish almost, I just felt the need to really like prove myself again.

Similar to the stories of these Asian American men, studies on Asian American men and masculinities reveal that Asian American men view sports and athleticism as masculine necessities (Chen, 1999; Lu, \& Wong, 2013).

\section{Conclusion}

The narratives of Asian American men showed that the intersectionalities of race and gender relations produced unique meanings when they participated in sports. Asian American men as racialized ethnic minorities in the U.S. face a set of ideas that continue to otherize them. Dealing with racial ideologies specific to their manhood was a regular part of the everyday lives of the interviewees. These racial ideologies perpetuate the hierarchy that traps Asian American men in the lower ranks of U.S. society. Within the complex interplay of various masculinities, subordinate masculinities such as Asian American men, gay and working class men, highlight hegemonic masculinity by contrasting with the ideal (Cornell, 2005). It is within this mechanism that Asian American men employ gender strategy to acquire powerful masculinity. Chen uses the term "hegemonic bargaining" to explain this strategy. Asian American men attain masculinity by "trading on (or benefiting from) the advantages conferred by his race, gender, sexuality, class, accent, and/or generational status to achieve manhood" (1999, p. 600).

Similar to findings of Chen's study, the Asian American men interviewed traded their ability to excel in sports to resist the images of typical Asian men as unwanted, inadequate and undesirable. Asian American men who embrace their identity as mainly "jocks" or "the soccer player" are manifesting the interplay of racial and gender intersections. By displaying traits of hegemonic masculinity, these Asian American men were able to avoid and resist the stereotypical notions of Asian American men. Asian American men experienced empowering and enriching experiences through sports as they were able to erase or at least distance themselves from the image of a typical Asian man by displaying opposing characteristics from the model minority myth. Some seemed to truly believe that they were apart from the rest of the Asian group as they themselves further otherized Asian men as reflected in Ji Hoon's comment "most Asian men are scrawny" and Dave's assertion "I don't know what it's like to be a typical Asian man because I am not one". Even to James, who admitted he was "this little Asian guy", displaying signs of hegemonic masculinity through swimming was an empowering experience.

The stories of these Asian American men suggested that being approved and acknowledged by their White peers was a prime motivator for participation in sports. Successful establishment of their status as racial minority men depended largely upon whether Whites perceived them as appropriate and acceptable.

Ironically, hegemonic bargaining by Asian American men also perpetuates the racial and gender hierarchy. The very acts of Asian American men conforming to hegemonic ideals in order to attain masculinity reinforce the notion of Asian American men as inadequate, undesirable and unwanted (Chen, 1999).

According to Hamamoto, minority members reject their own group and individual identity and accept instead "a White supremacist complex that establishes the primacy of Euro-American practice and social institutions" (Hamamoto, 1994, p. 2, also qtd. in Espiritu, 2008). Many stories of the interviewees support this thesis; identifying as a jock or athlete while distancing self-identity away from the usual Asian American perpetuates racial hierarchy and reinforces White superiority and supremacy. Consciously or unconsciously, the college age Asian American men were clearly aware of the uneven relationship between themselves and the students who belonged to the dominant White American group.

In short, the richly textured stories of these Asian American men provided a glimpse of what it was like to live as a racially marginalized person in the U. S. The interlocking categories of oppression created a unique situation for these Asian American men, who sought to avoid marginalization as effeminate racial minority people through participation in sports. The stories of their lives reflected the pain and struggle of encountering 
racism as a regular part of their lives. Sports served as a means to break away from the lower ranks of the racial and gender hierarchy assigned to Asian Americans and also as a way to acquire approval and acknowledgement from White peers. Ironically, their struggles to be accepted by their White peers resulted in perpetuating and reinforcing this very hierarchy, which continues to idealize and normalize the Eurocentric ideas about manhood.

\section{REFERENCES}

Anderson, E. (2005). In the game: Gay athletes and the cult of masculinity. Albany, NY: State University of New York Press.

Anderson, E., \& McCormack, M. (2010). Intersectionality, critical race theory, and American sporting oppression: Examining Black and gay athletes. Journal of Homosexuality, 57, 949-967.

Brown, K., \& Jackson, D. (2013). The history and conceptual elements of critical race theory. In M .Lynn, \& A. Dixon (Eds.), Handbook of critical race theory in education. New York, NY: Routledge.

Chen, A. (1999). Lives at the center of the periphery, lives at the periphery of the center: Chinese American masculinities and bargaining with hegemony. Gender, \& Society, 13, 584-607.

Cheng, C. (1996). We choose not to compete: The "merit" discourse in the selection process, and Asian and Asian American men and their masculinity. In C. Cheng (Ed.), Masculinities in organizations (pp.177-200). Thousand Oaks, CA: Sage.

Coakley, J. (2015). Sports in Society: Issues and controversies. New York: McGraw-Hill.

Chou, R., \&Feagin, J. (2015.) Myth of the model minority: Asian Americans facing racism ( $2^{\text {nd }}$ ed.). Boulder, CO: Paradigm.

Connell, R. W. (2005). Masculinities. 2nd ed. Berkeley: University of California Press.

Collins, P. (2000). Black feminist thought: Knowledge, consciousness, and the politics of empowerment ( $2^{\text {nd }}$ ed.). London: Routledge.

Crenshaw, K. (1991). Mapping the margins: Intersectionality, identity politics, and violence against women of color. Stanford Law Review, 43(6), 1241-1299.

Delgado, R. (Ed.) (1995). Critical race theory: The cutting edge. Philadelphia, PA: Temple University Press.

Eng, D. (2001). Racial castration: Managing masculinity in Asian America. Durham, NC: Duke University Press.

Espiritu, Y.L. (2008). Asian American women and men: Labor, laws, and love (2 $2^{\text {nd }}$ ed.). Lanham, MD: Rowman, \& Littlefield.

Fletcher, T. (2014). 'Does he look like a Paki?' an exploration of 'whiteness', positionality and reflexivity in interracial sports research, Qualitative research in sport, exercise and health, 6, 2, 244-260.

Gringeri C, Barusch, A., \& Cambron, C. (2013). Epistemology in qualitative social work research: A review of published articles, 2008-2010. Social work research, 37, 55-63.

Hamamoto, D. Y. (1994.) Monitored peril: Asian American and the politics of representation. Minneapolis, MN: University of Minnesota Press.

Harris, A. (1990). Race and essentialism in feminist legal theory. Stanford Law Review, 42, 581-616.

Hirose, A., \& Pih, K. (2010). Men who strike and men who submit: Hegemonic and marginalized masculinities in mixed martial arts. Men and masculinities. 13 (2) 190-209.

Hylton, K. (2005). 'Race', sport and leisure: Lessons from critical race theory. Leisure Studies, 24(1), 81-98.

Hylton, K. (2010). How a turn to critical race theory can contribute to our understanding of 'race', racism and antiracism in sport. International review for the sociology of sport, 45(3), 335-354.

Kibria, N. (2002). Becoming Asian American: Second-generation Chinese and Korean American identities. Baltimore MD: The Johns Hopkins University Press.

Kimmel, M. (2011). Manhood in America: A cultural history ( $3^{\text {rd }}$ ed.). New York: Free Press.

King, C.R. (Ed.) (2015). Asian American Athletes in Sport and Society. New York, NY: Routledge. 
King, C.R. (2006). Defacements/Effacements: Anti-Asian (American) sentiment in sport. Journal of sport and social issues. 30 (4) 340-352.

Lee, Y. (2015). Beyond black and white: Chinese American women's experience in sports. In C. King (Ed.), Asian American athletes in sport and society, pp.13-31 New York, NY: Routledge.

Lowe, L. (2000). Heterogeniety, hybridity, multiplicity, In J. Wu, \& M. Song (Eds.) Asian American studies: A reader, pp. 423-42. New Brunswick, NJ: Rutgers University Press.

Lu, A, \& Wong, J. (2013. Stressful experience of masculinity among U.S. born immigrants and Asian American men, Gender, \& Society, 27, 345-371.

Messner, M. (1992). Power at play: Sports and the problem of masculinity. Boston, MA: Beacon Press.

Patton, M. (1990). Qualitative evaluation and research methods. London: Sage Publications.

Shek, Y. (2006). Asian American masculinity: A review of literature. The Journal of Men's Studies, 14(3), 379-391.

Solorzano, D., \&Yosso, T. (2002). Critical race methodology: Counterstorytelling as an analytical framework for educational research. Qualitative studies in education, 14(4), 471-495.

Takaki, R. (1998). Strangers from a different shore. New York, NY: Little, Brown and Company.

Thangaraj, S. (2012). Playing through differences: black-white racial logic and negotiating South Asian American identity. Ethnic and Racial Studies, 35(6), 988-1006.

Thangaraj, S. (2015.) Desi hoop dreams: Pickup basketball and the making of Asian American masculinity. New York, NY: New York University Press.

Thangaraj, S., Arnaldo, C., \& Chin, C. (Eds.) (2016). Asian American sporting cultures. New York, NY: New York University press.

Tizon, A. (2014.) Big little man: In search of my Asian self. New York, NY: Houghton Mifflin Harcourt

U.S. Census Bureau (2012). The Asian population: 2010. Retrieved May 5, 2015, from https://www.census.gov/prod/cen2010/briefs/c2010br-11.pdf

Wu, F. (2002). Yellow: Race in American beyond Black and White. New York, NY: Basic Books.

AUTHOR'S ADDRESS: $\quad$ Yomee Lee

Kinesiology Department

State University of New York, Cortland

1161 The Professional Studies Building

P.O. Box 2000

Cortland, NY 13045

U.S.A.

E-mail: yomee.lee@cortland.edu

Received: 6 October 2016; Accepted: 20 November 2016 